\title{
Simulation and Testing of Cylindrical Magnetic Turbine Design at the Center for Innovation and Certification (CIC) \\ ${ }^{* 1}$ Fitria Hidayanti, ${ }^{2}$ Erna Kusuma Wati \\ 1,2 Engineering Physics Department, Universitas Nasional, Indonesia Jalan Sawo Manila No. 61, Pasar Minggu, Jakarta 12520 \\ Email: fitriahidayanti@gmail.com, ernakusuma.w@gmail.com
}

Received: 11th November 2019, Accepted: 26th December 2019, Published: 29th February 2020

\begin{abstract}
Cylindrical magnetic turbine design with a stator diameter of $13.7 \mathrm{~cm}$ and a rotor diameter of $10.7 \mathrm{~cm}$ has a distance between the magnets on the rotor and stator is $1.7 \mathrm{~cm}$ with zigzag configuration. Turbine simulation with FEMM 4.2 results the largest density flux can be between 5.091e-001 - 5.690e-001 Tesla, with the value of the thrust on the $\mathrm{x}$-axis having a maximum value of $0.0976232 \mathrm{~N}$, while the $\mathrm{y}$-axis has a maximum value of 0.067278 $\mathrm{N}$. Torque the maximum obtained in a magnetic turbine is 0.5011 Newton meter. Direct testing results magnetic turbines have a maximum turbine rotation speed $12.22-12.92 \mathrm{rpm}$ with a rotation time $14-16$ seconds.
\end{abstract}

Keywords

Magnetic Turbine, Turbine Rotation, Rotation Time, Density Flux

\section{Introduction}

The magnetic turbine is a turbine that is driven using the principle of a magnetic field when the conditions of the two same or different magnetic poles meet, there will be repulsion or attraction between the magnetic poles [1, 2]. This principle is used to drive rotors on magnetic turbines. In magnetic turbines, the magnetic force is produced by permanent magnets $(\mathrm{NdFeB})$ contained in the rotor and stator [3]. This research designs an optimal cylindrical magnetic turbine design until rotate. Magnetic turbine simulation uses FEMM 4.2 software and direct testing in the field with a tachometer. The variables analyzed in FEMM 4.2 software simulation are the magnetic field, turbine thrust and torque on the turbine.

The magnetism of a material depends on the moment of the electron spin in its constituent elements $[4,5]$. The international unit for magnetic field strength is Tesla $(\mathrm{T})$ where 1 Tesla is defined as $1 \mathrm{~N} /(\mathrm{C} . \mathrm{m} / \mathrm{s})$ or $1 \mathrm{~N} /(\mathrm{A} . \mathrm{m})$ so that the magnetic force can be formulated as $\mathrm{F}=|\mathrm{q}| \mathrm{vB} \sin \theta$ [6]. A magnetic field is a field where there is a magnetic force. A magnetic field can be generated when an electric charge carrier such as electrons moves through space or in an electrical conductor. The geometric shapes of the magnetic flux lines produced by moving the charge carrier (electric current) are similar to the shape of the flux lines in the electrostatic field [7].

Neodymium Iron Boron $(\mathrm{NdFeB})$ is the strongest permanent magnet that is most widely used. As the name implies, this magnet is made of Neodymium, Iron, and Boron metal to make $\mathrm{Nd} 2 \mathrm{Fe} 14 \mathrm{~B}$ with a tetragonal crystalline-shaped structure. This magnet has magnetic energy reaching $50 \mathrm{MGOe}$ or about 15 kilo-gauss.

\section{Magnetic Turbine}

Magnetic Turbine is a turbine that utilizes magnetic force as the driving force. Simply put, magnetic turbines use the opposite of the principle of a DC motor [8]. Magnetic turbines can be used as a single energy source or as a secondary energy source. The secondary energy source here, namely the magnetic turbine, is a system that can streamline or produce additional energy which is greater than the input energy. An example of a magnetic turbine as secondary energy is John Ecklin's Magnetic Shielding Generator [9].

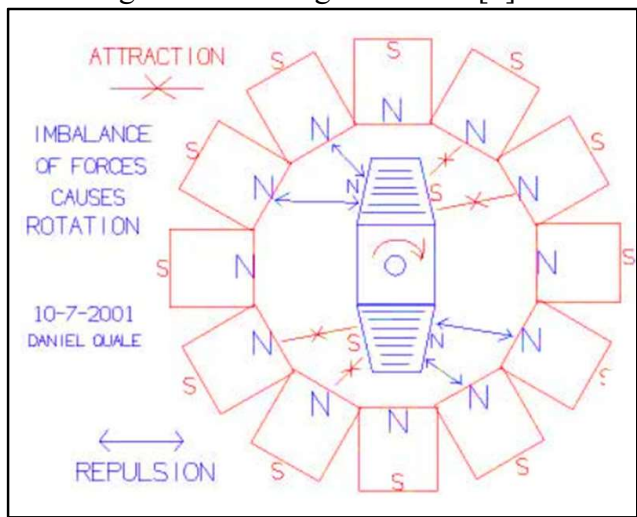

Figure 1: Magnetic Turbine Configuration 
Examples of magnetic turbines as a primary energy source are motor magnets made by Muammer Yildiz as shown in Figure 1 [10]. This magnetic turbine works using the principle of the magnetic field. When the conditions of the two same or different magnetic poles meet, there will be repulsion or attraction between the magnetic poles. This principle is used to drive rotors on magnetic turbines. There are two magnetic fields in a magnetic turbine, one is produced by a stator and the other is produced by a rotor. The force will be induced in the rotor to change and adjust to the stator magnetic field, this will cause the rotor to move or rotate away from the stator magnetic field in the turbine so that it will produce rotational motion in the rotor. Configuration of the placement of magnets on the rotor and stator must be placed with a certain configuration so that the rotor can rotate continuously. The angular speed of the rotor is directly proportional to the strength of the magnetic field and the distance of the magnets to the rotor and stator.

\section{FEMM Software 4.2}

Finite Element Method Magntics 4.2 is an application used to analyze the magnetic field characteristics of a material. Magnetic turbine design that has been designed using Autodesk ${ }^{\circledR}$ Inventor, is then simulated in FEMM 4.2 Software to analyze the magnetic field characteristics contained in the turbine design.

\section{Materials and Methods}

The cylindrical magnetic turbine model in this study was designed using the Autodesk Inventor application. This magnetic turbine design has a rotor with a diameter of $10.7 \mathrm{~cm}$ and a stator with a diameter of $13.7 \mathrm{~cm}$. The distance between magnets on the rotor and stator is $1.7 \mathrm{~cm}$ with zigzag configuration between magnets. The drawing model of magnetic turbine prototype is shown in Figure 2.

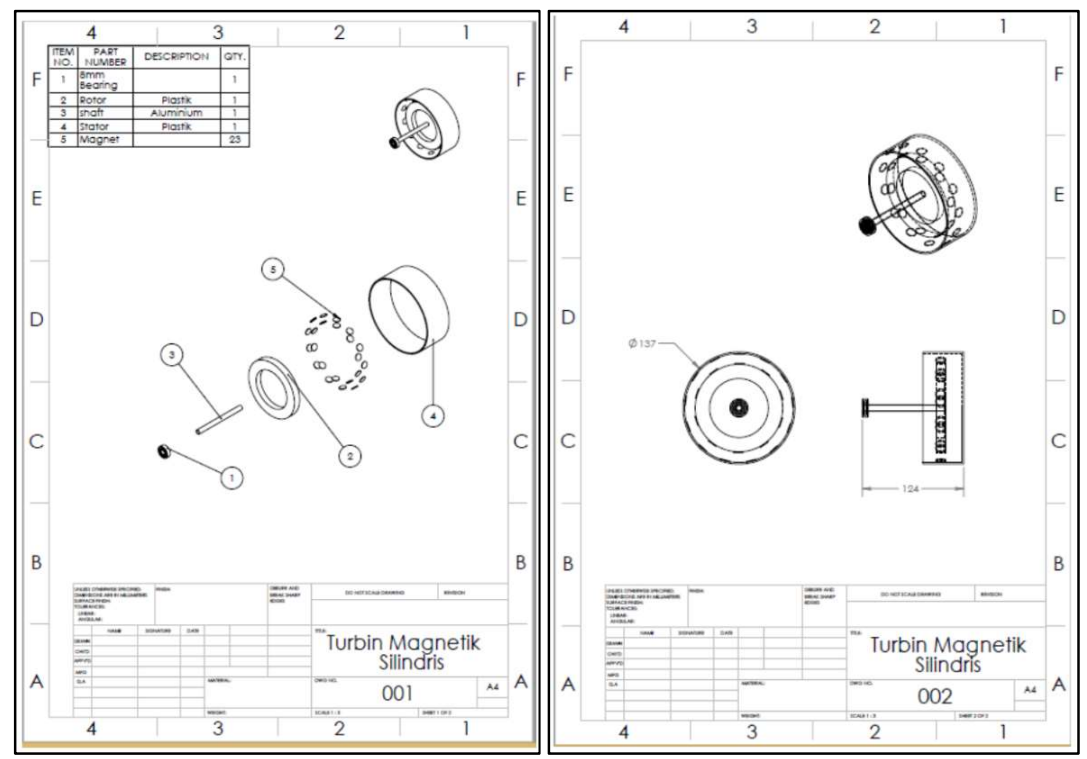

Figure 2: Drawing of Magnetic Turbine Prototype

\section{Prototype}

Making a prototype begins with the selection of raw materials. The raw material for the stator is polypropylene (PP) plastic in the form of a jar. This is because the cylindrical shape and the nature of the plastic are not affected by magnetic fields (nonmagnetic). $\mathrm{NdFeB}$ magnets with a diameter of $1.2 \mathrm{~cm}$ and a thickness of $1 \mathrm{~mm}$ with a total of $15 \mathrm{pcs}$, then mounted on one part of the plastic stator (consisting of 2 parts) by making a slot on the stator that matches the size of the magnet. The distance between the magnets on the stator is $2 \mathrm{~cm}$. This is based on the experiments the farthest distance that is still affected by the magnetic field, two magnets with the poles reject closer slowly until other magnets begin to be displaced from this experiment obtained the farthest distance that is still affected by a strong magnetic field is $2 \mathrm{~cm}$. The prototype is shown in Figure 3. 

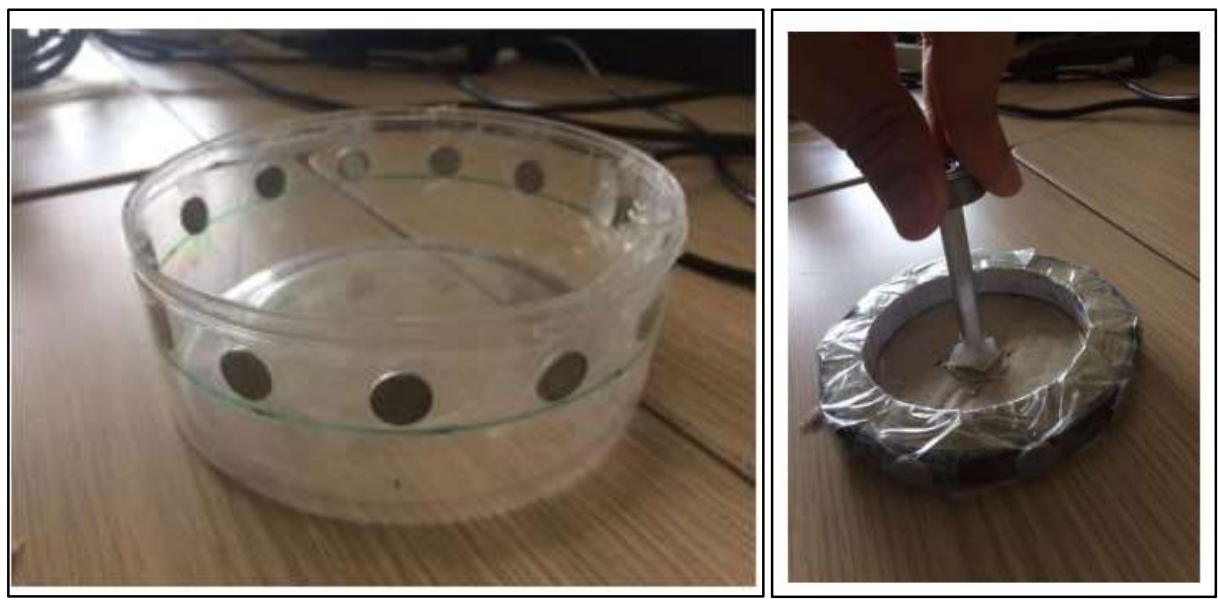

Figure 3: Prototype One Piece Stator (left) and Rotor (right)

The raw material for rotors is cylindrical polypropylene (PP) plastic. The rotor is then mounted with a $\mathrm{NdFeB}$ magnet with the same dimensions as the stator, but with a pole opposite the stator. This is done to create a repulsive force-resisting between magnets resulting in thrust on the rotor. Magnets mounted on the rotor are ten pieces, with the distance between magnets is $2 \mathrm{~cm}$.

The turbine shaft is made of an aluminium hollow rod (cylindrical with a hole in the middle). The choice of aluminium material is due to its light and strong weight, as well as its material which has diamagnetic properties. Aluminium rod used is $8 \mathrm{~mm}$ in diameter, the bearings used follow the dimensions of the aluminium rod, the Nachi $628 \mathrm{Z}$ with an inner diameter of $8 \mathrm{~mm}$. The specifications of magnetic turbine prototype is shown in Table 1 .

\begin{tabular}{|c|l|c|c|}
\hline Part & \multicolumn{1}{|c|}{ Dimension } & Material & Total \\
\hline Stator & $\begin{array}{l}\text { Diameter } 13.7 \mathrm{~cm} \\
\text { Circle circumference } 43.10 \mathrm{~cm}\end{array}$ & Plastic \\
\hline Rotor & $\begin{array}{l}\text { Diameter } 10.7 \mathrm{~cm} \\
\text { Circle circumference } 33.63 \mathrm{~cm}\end{array}$ & Plastic & 1 \\
\hline Shaft & Diameter $8 \mathrm{~mm}$ & - & 1 \\
\hline Bearing (Nachi 628Z) & Diameter $8 \mathrm{~mm}$ & - & 1 \\
\hline Magnet & $\begin{array}{l}\text { Thickness } 1 \mathrm{~mm} \\
\text { Diameter } 1.2 \mathrm{~cm}\end{array}$ & $\begin{array}{l}\text { Stator } 13 \\
\text { Rotor } 10\end{array}$ \\
\hline
\end{tabular}

Table 1: Specifications of Magnetic Turbine Prototype

\section{Magnetic Turbine Testing Procedure}

Tool testing is carried out in the following stages:

a. Install a magnetic turbine with a DC motor connected to the power supply. The DC motor acts as a starter or trigger for the motion of magnetic turbines. DC motors and magnetic turbines are connected through shafts.

b. The DC motor is connected to the power supply for 1 second and then disconnected. It is intended that the magnetic turbine rotates, purely using a magnetic force.

c. Data were measured in the form of RPM and the length of time the turbine rotates.

d. The input voltage of the power supply used is $2.5 \mathrm{~V}$.

\section{Results and Discussion}

Based on the magnetic turbine made, the following results are obtained from the research as shown in Table 2.

\begin{tabular}{|c|c|c|}
\hline $\begin{array}{c}\text { Starter Power Supply } \\
\text { Voltage (V) }\end{array}$ & $\begin{array}{c}\text { Max Speed of Turbine Rotation } \\
(\mathrm{rpm})\end{array}$ & Time Rotation (s) \\
\hline \multirow{4}{*}{2.5} & 12.72 & 15.640 \\
\cline { 2 - 3 } & 12.22 & 14.950 \\
\cline { 2 - 3 } & 13.11 & 16.050 \\
\cline { 2 - 3 } & 13.15 & 16.020 \\
\cline { 2 - 3 } & 12.92 & 15.880 \\
\hline
\end{tabular}

Tabel 2: Results of Research Data Retrieval 
From the results of research data, it can be seen that magnetic turbines have a maximum turbine rotation speed ranging from 12.22 - $12.92 \mathrm{rpm}$ with a rotation time between 14 - 16 seconds.

\begin{tabular}{|c|c|}
\hline Magnet & $\begin{array}{c}\text { Remanence/Magnetic flux } \\
\text { density (killo-Gauss) }\end{array}$ \\
\hline 1 & 8.1 \\
\hline 2 & 8.2 \\
\hline 3 & $7, .9$ \\
\hline 4 & 7.8 \\
\hline 5 & 8.1 \\
\hline 6 & 7.9 \\
\hline 7 & 8.3 \\
\hline 8 & 8.5 \\
\hline 9 & 8.4 \\
\hline 10 & 8.2 \\
\hline 11 & 7.9 \\
\hline 12 & 8.0 \\
\hline 13 & 8.3 \\
\hline 14 & 7.6 \\
\hline 15 & 7.9 \\
\hline 16 & 8.2 \\
\hline 17 & 8.3 \\
\hline 18 & 7.9 \\
\hline 19 & 7.9 \\
\hline 20 & 8.1 \\
\hline 21 & 8.1 \\
\hline 22 & 8.1 \\
\hline 23 & 8.2 \\
\hline
\end{tabular}

Table 3: Remanence Measurement Results with Gauss-Meter on each Magnet

From the measurement data with gauss-meter, the value of magnetic flux density per magnetic turbine is between 7.6 - 8.5 kilo-gauss.

\section{Simulation with FEMM Software 4.2}

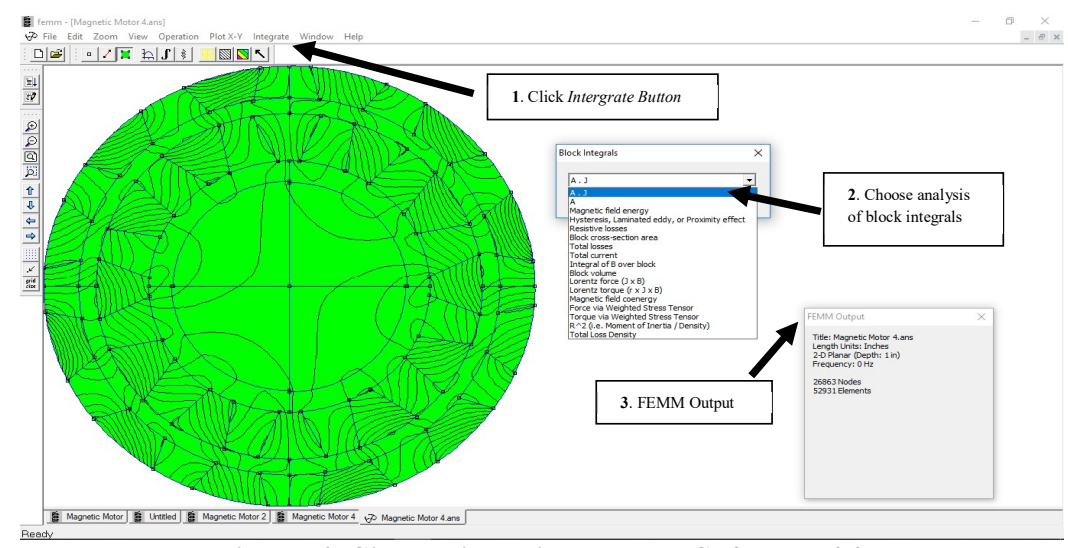

Figure 4: Simulation with FEMM Software 4.2

The results of the analysis that want to be displayed in this magnetic turbine simulation are only torque and force acting on the $\mathrm{x}$ - and $\mathrm{y}$-axes of the turbine rotor. FEMM 4.2 software simulation and analysis results show that the turbine thrust on the $\mathrm{x}$-axis has a maximum value of $0.0976232 \mathrm{~N}$, while the $\mathrm{y}$-axis has a maximum value of $0.067278 \mathrm{~N}$. The maximum torque obtained on the magnetic turbine is 0.5011 Newton meter.

\section{Conclusions}

Turbine simulation with FEMM 4.2 results the largest value of density flux can be between 5.091E-001 - 5.690E001 Tesla, with the value of the thrust on the $\mathrm{x}$-axis having a maximum value of $0.0976232 \mathrm{~N}$, while the $\mathrm{y}$-axis 
has a maximum value of $0.067278 \mathrm{~N}$. Torque the maximum obtained in a magnetic turbine is 0.5011 Newton meter. Direct testing results magnetic turbines have a maximum turbine rotation speed $12.22-12.92 \mathrm{rpm}$ with a rotation time 14 - 16 seconds.

Acknowledgements

The authors acknowledge for editor and reviewers. Thank you for useful discussions with our colleagues in the Faculty of Engineering and Science, University Nasional, Jakarta, Indonesia. Thank you for Research and Community Service (LPPM) Universitas Nasional, Jakarta for the support.

\section{References}

1. Buschow, K.H.J. and F.R. Boer, Physics of magnetism and magnetic materials. Vol. 7. 2003: Springer.

2. Schobert, H.H., Energy and society: An introduction. 2014: CRC Press.

3. Serway, R.A. and J.W. Jewett, Study Guide with Student Solutions Manual, Volume 1 for Serway/Jewett s Physics for Scientists and Engineers, 9th. Vol. 1. 2016: Nelson Education.

4. Polinder, H., G. Van Bussel, and M. Dubois. Design of a PM generator for the Turby, a wind turbine for the built environment. in Proceedings of ICEM 2004. 2004.

5. Brück, E., et al., Magnetic refrigeration near room temperature with Fe2P-based compounds. Journal of alloys and compounds, 2004. 383(1-2): p. 32-36.

6. Serway, R.A., et al., Current and resistance. Physics for scientists and engineers with modern physics., 2014: p. 808-832.

7. Furlani, E.P., Permanent magnet and electromechanical devices: materials, analysis, and applications. 2001: Academic press.

8. Gieras, J.F., Permanent magnet motor technology: design and applications. 2009: CRC press.

9. $\quad$ Ecklin, J.W., Permanent magnet motion conversion device. 1975, Google Patents.

10. Ali, A.H. and A.N.C. Ismail, Design and Simulation of Self-Running Magnetic Motor. Journal of Engineering Technology, 2017. 5: p. 27-31. 